\title{
A low priming volume oxygenator for bloodless priming in cardiopulmonary bypass
}

\author{
E. PROCTOR ANDA. H. DE BONO ${ }^{1}$ \\ From the Thoracic Research Department, Guy's Hospital, London
}

The oxygenator described here arose out of the need to dispense with homologous blood in animal perfusions. It was considered that this could best be attained with an oxygenator having a priming volume sufficiently small to allow the use of isotonic solutions without undue dilution and consistent with full gas exchange and adequate temperature control.

It was recognized that modifications to existing machines were unlikely to reduce the priming volume sufficiently to allow of total haemodilution without a significant reduction in their performance. As a result the following design was evolved (Figs 1 and 2).

An annular bubble column was devised as the most practical method of attaining efficient gas exchange with a small amount of blood. The annulus increases 'lift' and mixing in the vertical tube and allows of full oxygenation at flows of up to $2.51 . / \mathrm{min}$. (in the small model shown here) at normal temperature with only $300 \mathrm{ml}$. of blood in transit through the annular column.

Since temperature control is an essential function of cardiopulmonary bypass, both in normothermic and hypothermic perfusions, an appreciable volume of priming blood is usually involved in heat exchange. This volume was eliminated by using the inner surface of the annulus for heat exchange.

The efficiency of the bubble type of oxygenator is usually offset by the large volume of blood required for debubbling by settling reservoirs after antifoaming. This volume was considerably reduced by efficient antifoaming, by low-pressure filtration, and by the use of a sump reservoir with an additional filter which together prevent vortex formation in the reservoir.

Present address: Department of Experimental Surgery, Hammersmith Hospital, London, W.12

FIG. 1. Side view of oxygenator showing stainless steel heat exchanger in vertical bubbling column.

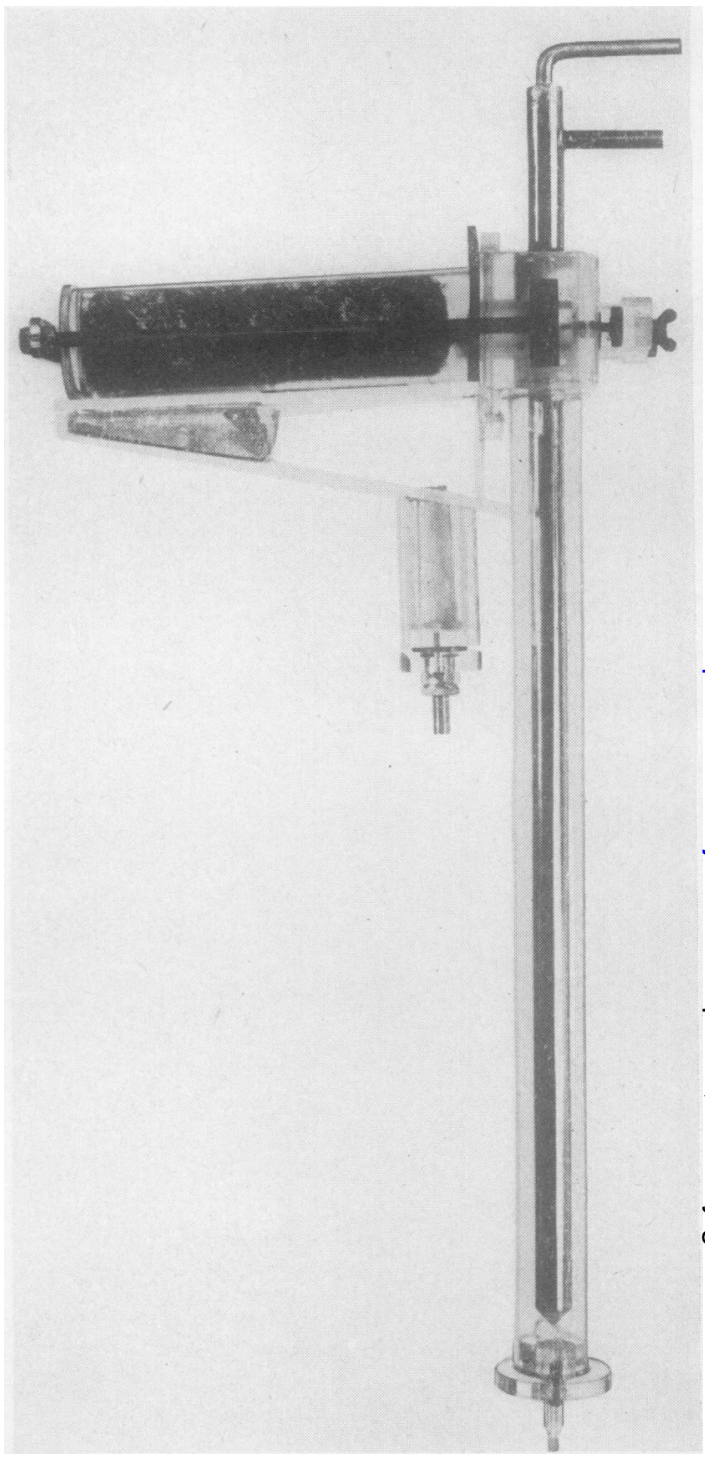




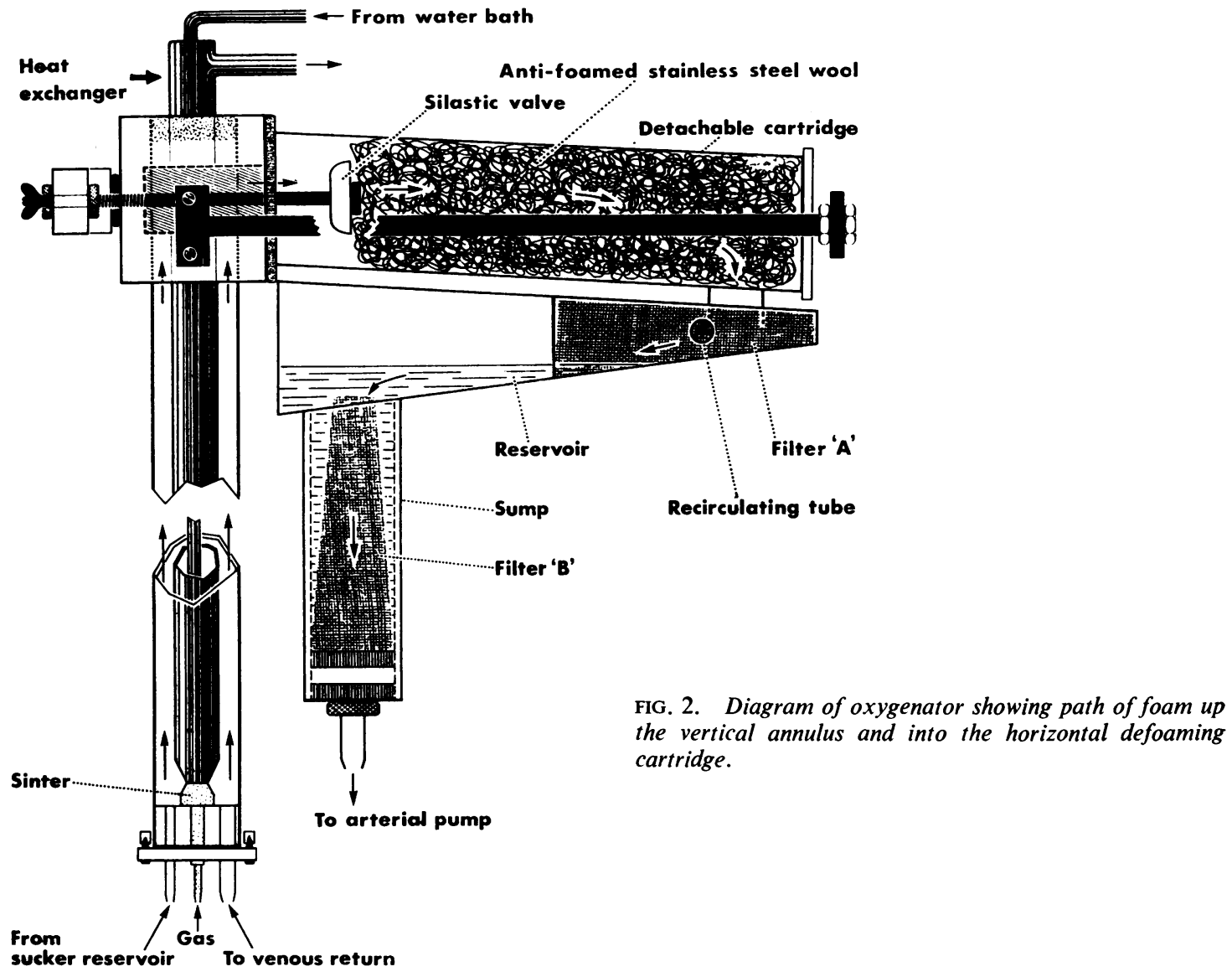

FIG. 3. View of oxygenator showing valve control mechanism. The far side valve is open into the far cartridge.

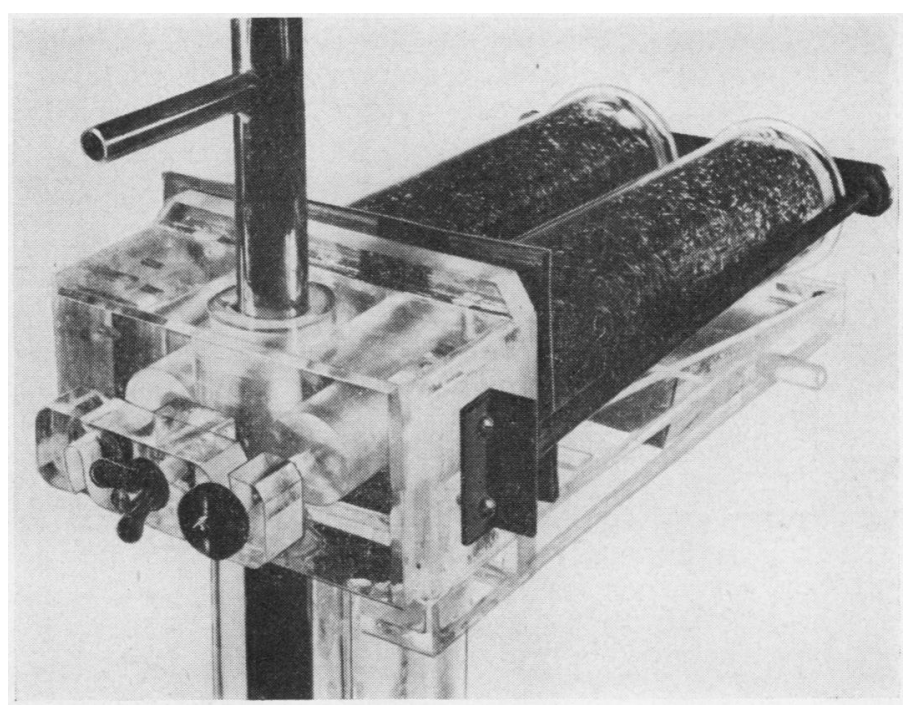




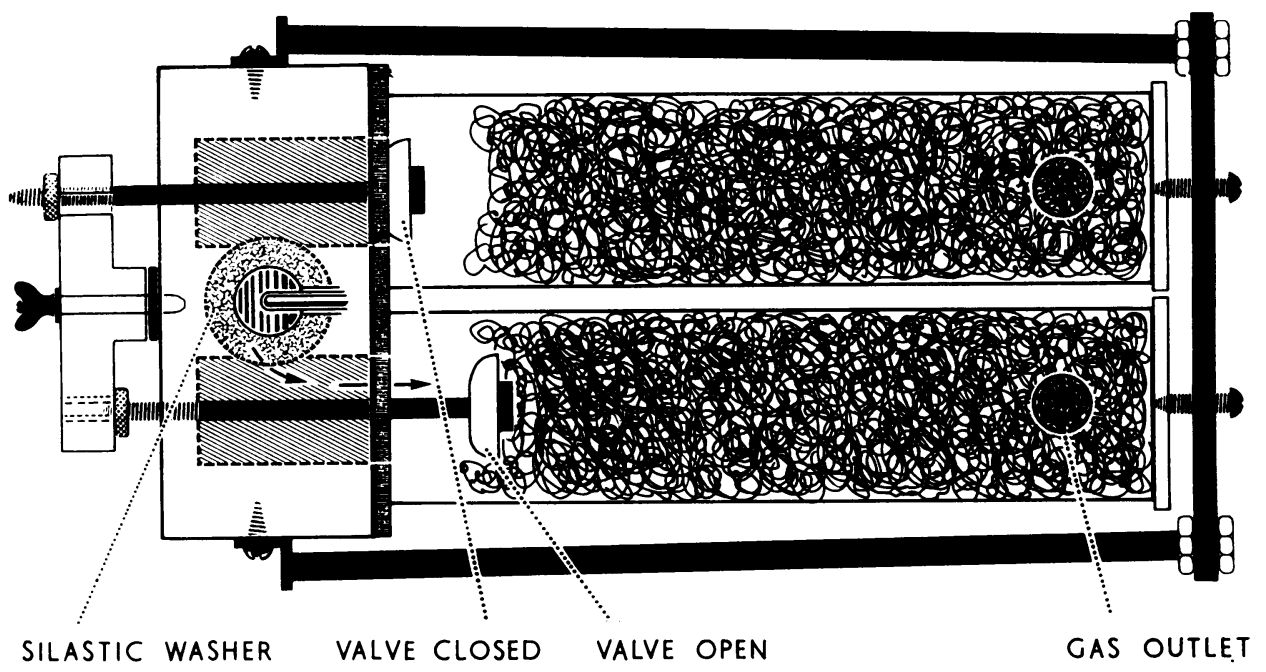

FIG. 4. Diagram of twin cartridges from above showing path of foam from annulus into one of the defoaming cartridges. The valve mechanism allows only one cartridge to be used at a time and permits of the replacement of a used cartridge without stopping the blood flow by releasing the screw at the distal end of the cartridge.

A theoretical disadvantage of bubble oxygenators has been the limited life of the antifoaming apparatus in extended perfusions. This problem has been overcome in two ways: (1) An improvement in antifoaming properties and adhesion due to baking $20 \%$ Antifoam A on to the surface of scrupulously clean stainless steel wool at a temperature of $200^{\circ} \mathrm{C}$. for four to six hours. This gives a 'rubbery' texture to the silicone surface and improves both the antifoaming and adhesive qualities of the surface. The usual technique of dipping, drying, and autoclaving (McGregor, 1960) imparts a less adherent, greasy surface. It should be noted, however, that this improvement is not sustained at higher temperatures, since at $320^{\circ} \mathrm{C}$. and above the silicone surface becomes brittle and fragments with movement. The surface resulting from baking at $200^{\circ} \mathrm{C}$. is sufficient for up to six hours' efficient antifoaming with the type of cartridge described. (2) By using twin antifoaming cartridges (Figs 3 and 4) which can be switched alternately into the foam path, the antifoaming time can be simply doubled to 12 hours. Should the need arise for extended perfusions beyond 12 hours - as in long-term, partial, closedchest perfusions for circulatory support-the cartridges can be replaced without stopping the perfusion, thereby conferring an indefinite running time limited only by the trauma to the blood. Our experience in this field is as yet limited to 10 hours.
As a result of these features the oxygenator has a priming volume of $500 \mathrm{ml}$. plus $250 \mathrm{ml}$. in the arterial and venous lines, a total of $750 \mathrm{ml}$. This is sufficient to initiate and maintain total bypass of up to $2.51 . / \mathrm{min}$. in dogs of 20 to $30 \mathrm{~kg}$. The system can therefore be primed with buffered electrolyte solutions (Ringer-Locke, RingerLactate), low molecular weight dextran, or combinations of these while maintaining full gas exchange and adequate temperature control for normothermia, mild hypothermia, and slow profound hypothermia.

As an approximate guide to the degree of haemodilution involved, the average haematocrit values for the usual one to two hours' total perfusion are: pre-bypass, $44 \%$; during bypass, $33 \%$; and 24 hours after bypass, $41 \%$. At no time has it been necessary to add blood either during bypass or post-operatively.

Although the oxygenator has so far been used only for animal perfusions, a larger model designed for flows of 4 to $51 . / \mathrm{min}$. with an estimated priming volume of 1.2 to 1.51 . RingerLocke, etc., is in hand.

\section{DESCRIPTION}

The annulus for oxygenation and heat exchange is formed by the insertion of a thin-walled stainless steel tube into a vertical perspex tube. It is centralized and supported by the gas sinter at the bottom and a silastic 
washer at the top. Sucker reservoir and venous lines enter at the bottom of the tube.

OXYGENATION Gas, usually $97 \%$ oxygen and $3 \%$ carbon dioxide, enters through a sinter to give bubbles of approximately $3 \mathrm{~mm}$. diameter which foam and lift the blood up the annulus to a large port at the top of the column where it is directed by the valves into one of the antifoaming cartridges. With a ratio of 4 to 5 litres of gas flow per litre of blood flow the oxygen saturations are 97 to $99 \%$ (arterial) and 70 to $74 \%$ (venous) at flows up to $2.51 . / \mathrm{min}$. in $20-30 \mathrm{~kg}$. dogs at normothermia.

HEAT EXCHANGE The stainless steel tube forms the inner surface of the annulus, and water from the appropriate water-bath emerges at the bottom via the narrow central tube and flows up between it and the inner surface. The efficiency of heat exchange obviously depends on a variety of factors-water flow, blood flow, temperature gradient, size of animal, etc. -but with a dog weighing $20 \mathrm{~kg} ., 21 . / \mathrm{min}$. blood flow, and a water-bath temperature of $1-3^{\circ} \mathrm{C}$. the temperature of the blood drops approximately $7^{\circ} \mathrm{C}$. in transit through the annulus in the range $20^{\circ} \mathrm{C}$. to $36^{\circ}$ C. This will result in cooling the animal at $0.7^{\circ} \mathrm{C}$. $/ \mathrm{min}$. over the same range. Equally, a waterbath temperature of $38.5^{\circ} \mathrm{C}$. will maintain normothermia.

ANTIFOAMING This occurs in the sloping cylindrical cartridges. The cylindrical shape allows of a good fit for the balls of stainless steel wool, a constant area of silicone in contact with the blood, and no 'short-cuts' for the foam. The rate of advance of the foam through the cartridge is about 1 inch per hour.

RESERVOIR The defoamed blood enters the reservoir at the distal end. This reservoir has a sloping floor and is narrower at the lower end. A stainless steel filter ' $A$ ' is placed at the upper end of the reservoir. It has two functions ; it filters the blood at low pressure and it slows up and evenly distributes the blood as it flows down the slope, thus preventing the formation of bubbles in the reservoir. The sump reservoir maintains a level of 5 to 6 inches between the surface of the blood and the outflow into the arterial roller pump. This, plus the additional filter 'B', eliminates the danger of vortex formation due to suction from the arterial pump. A re-circulating line connects the arterial line with the reservoir.

ESSENTIAL DIMENSIONS These are as follows:

Bubbling Column

Length from sinter to outflow port, 26 in.

Internal diameter, 1.75 in.

Heat Exchanger

Outside diameter, 1 in.

20 gauge highly polished stainless steel.

Annulus

Width, 0.375 in.

\section{Reservoir}

Length, $11 \cdot 5$ in.

Width at upper end, 6 in.

Width at sump, 2.5 in.

Depth, $2 \cdot 5$ in.

Volume, 1 litre.

Sump

Depth, 4 in.

Internal diameter, 1.25 in.

Filters

80 gauge mesh stainless steel.

Cartridges

Length, 11 in.

Internal diameter, $2 \cdot 5$ in.

Sinter

50 holes 0.021 in. diameter.

\section{METHOD OF USE}

The reservoir is primed with $750 \mathrm{ml}$. of fluid, RingerLocke, Ringer-Lactate, or low molecular weight dextran (Rheomacrodex ${ }^{1}$ ). The $p H$ at $20^{\circ}$ C. of Ringer-Locke is 7.52 ; of Ringer-Lactate, 6.55; and of $10 \%$ low molecular weight dextran in dextrose, 5.35 (mainly due to the dextrose). We normally use a mixture of $550 \mathrm{ml}$. Ringer-Lactate and $200 \mathrm{ml}$. dextran. The $p \mathrm{H}$ of this mixture is 6.39 at $20^{\circ} \mathrm{C}$. and $1 \mathrm{mEq}$ of sodium bicarbonate converts this to $7 \cdot 39$. Since the liver is less able to metabolize lactate at low temperatures, we tend to use Ringer-Locke in place of Ringer-Lactate for profound hypothermia.

The arteriovenous loop is filled by attaching the venous end of the loop to the re-circulating tube at the side of the reservoir and pumping the fluid through the lines and back into the reservoir. The venous line is then connected to the bottom of the bubbling tube. With the gas line, sucker reservoir line, and heat exchanger lines appropriately connected, the valve into one of the cartridges is opened and the oxygenator is ready for bypass.

Since the vertical bubbling tube is empty at the start of bypass, the arterial pump is started very slowly as blood from the venous line has to traverse the annulus, be defoamed and enter the reservoir (usually 7 to 8 seconds) before the arterial pump speed can be increased. Seven hundred and fifty millilitres of fluid is sufficient to initiate and maintain bypass, but over a two-hour perfusion up to 300 $\mathrm{ml}$. may be added to replace fluid losses, operative, metabolic, urinary, and respiratory.

At the end of the bypass, after establishing the required arterial and venous pressures, the blood remaining in the oxygenator is bottled and returned to the animal as required.

CLEANING AND STERILIZING All tubing is discarded and the oxygenator is rinsed with tap water. After thorough cleaning the oxygenator and all components,

\footnotetext{
'Pharmacia (Great Britain) Ltd., Sinclair House, The Avenue,
} West Ealing, London, W.13 
steel and plastic, are immersed in a $20 \%$ solution of sodium hydroxide for a minimum of 12 hours. They are then rinsed with tap water. dilute hydrochloric acid, tap water, and then distilled water in turn to remove any traces of protein material. The component parts are then dried with hot air and assembled complete with tubing ready for sterilization. The stainless steel wool is separately stripped of its silicone and protein surface by immersion in a $20 \%$ solution of sodium hydroxide for 48 hours. A stock of siliconed stainless steel wool is kept and the used wool is allowed to accumulate until enough is available for re-siliconizing, usually once every few weeks.

Since the oxygenator is at present largely made of perspex, it is sterilized with ethylene oxide gas when assembled.

\section{RESULTS}

Over 50 perfusions have been successfully carried out with this oxygenator in dogs, from a total bypass of two hours for valve replacement to closedchest partial by-pass (50 to $70 \%$ of total) of up to 10 hours for circulatory support. They are to be described in a later paper.

\section{DISCUSSION}

Apart from the convenience and advantages of total haemodilution techniques in animal perfusions, a low dilution, bloodless prime bypass machine with adequate heat exchange, which can also be sterilized, lends itself to a variety of clinical applications, both elective and emergency.

ELECTIVE These derive from haemodilution.

(1) Reduction in the amount of fresh, heparinized, blood required for bypass.

(2) Reduction in possible morbidity arising from the use of large quantities of homologous blood.

(3) Patients with rare blood groups.

(4) Patients who regard blood transfusion as violating their religious precepts, e.g., Jehovah's Witnesses (Cooley, Beall, and Grondin, 1962).
Patients in group 4 and occasionally those in group 3 (in common with the animal perfusions) would receive no blood either during bypass or post-operatively.

EMERGENCY These derive from the immediate availability of a bloodless priming system.

(1) Conversion of a 'closed' to an 'open' technique during the course of an operation should it become necessary. The oxygenator could be standing by. When required it could be primed with Ringer-dextran type solutions within a few minutes. Total bypass could be initiated and, in many, maintained without the addition of blood.

(2) Closed chest circulatory support (via one femoral artery and vein) in severe pulmonary oedema, pulmonary embolus, and ischaemic heart disease for periods of the order of 12 to 24 hours, and which, in the absence of thoracotomy, need require no blood during this period. Our experience in this field is limited as yet to 10 hours.

\section{SUMMARY}

A simple sterilizable, low priming volume, bubble oxygenator using an annulus for oxygenation and heat exchange is described. Its performance and convenience in animal perfusions without recourse to homologous blood is outlined and its potential for clinical use, both elective and emergency, is noted.

We are grateful to Lord Brock for his support in this work ; also to the technicians, R. Magnus, D. Phelan, A. Smith, and G. Matthews, for their assistance.

\section{REFERENCES}

Cooley, D. A., Beall, A. C., and Grondin, P. (1962). Open-heart operations with disposable oxygenators, $5 \%$ dextrcse prime, and normothermia. Surgery, 52, 713 .

McGregor. R. R. (1960). Silicone defoamers in blood oxygenators Bull. Dow Corning Center Aid med. Res., 2, 6 